\title{
Fernández, Joaquín. 2008. El Ibañismo. Un caso de populismo en la política chilena (1937-1952). Santiago: Instituto de Historia de la Pontificia Universidad Católica de Chile, 214 pp.
}

\author{
DiEgo BARRÍA TRAVERSO \\ dbarria@uchile.cl
}

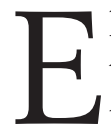

1 proceso político chileno ha sido destacado, por varios autores, debido a la temprana formación de un sistema de partidos políticos, y la existencia de un juego político que incrementalmente tomó características democráticas (Scully, 1992, Valenzuela, 1995). Durante el siglo XX esto llevó a que Chile, según mediciones comparativas, apareciera como uno de los países más democráticos del mundo (Valenzuela y Valenzuela, 1983: 8).

La preponderancia que ha tenido esta mirada ha traído como resultado que ciertos rasgos del sistema político chileno, no contradictorios con la tesis de la temprana institucionalización como la existencia de estamentos tecnocráticos actuando en política (Silva, 2006) o la existencia de liderazgos populistas, hayan sido olvidados.

Con la intención de soslayar la ausencia del populismo en el análisis de la política chilena, Joaquín Fernández aborda el problema del ibañismo, en tanto movimiento populista, dentro de la política chilena. El Ibañismo. Un caso de populismo en la política chilena (1937-1952) analiza, prestando especial atención a las campañas electorales de 1938, 1942 y 1952, la trayectoria del conjunto de movimientos y sectores que, por más de 15 años, se alinearon con Carlos Ibáñez del Campo en sus intentos por acceder a La Moneda, a través de elecciones. El objeto de estudio es del todo interesante, sobre todo si se tiene en cuenta que la figura en cuestión gobernó al país, tanto autoritaria como democráticamente, y que en la década de 1920 participó en la modernización de la actividad política y de la administración pública.

Fernández inicia su trabajo aceptando la validez de las tesis que plantean que el sistema de partidos chileno tiene características similares con los existentes en Europa occidental, pero, al mismo tiempo, advierte que esa misma interpretación “...adolece de algunas fallas, debido a que minimiza el rol jugado por los fenómenos populistas y los liderazgos personalistas en el Chile del siglo XX” (p. 21).

Según Fernández, un liderazgo populista pudo emerger en Chile debido a la existencia de dos factores. Por una parte, por la fuerza que el discurso nacionalista adquirió en las primeras décadas del siglo XX. Por otro lado, el electorado chileno se caracterizaba por su independencia de los partidos. Se calcula que sólo uno de cada diez votantes militaba en un partido (p. 25). Sumados estos dos 
factores, existía un espacio para que surgiera un liderazgo, alejado de los partidos, que utilizara el discurso nacionalista. Ibáñez del Campo fue quien aprovechó la oportunidad.

En la interpretación del autor, el ibañismo fue una corriente política que, a partir de la figura del líder, "...interpeló a la gente común, aislada de la actividad política. Invocando un lenguaje y una ritualidad política patrióticos, apeló a una cultura nacionalista común presente en el electorado chileno. De este modo intentó superar las divisiones partidistas, clasistas y religiosas de los ciudadanos y ampliar así su base de apoyo" (p. 27).

Este movimiento debió organizarse, aunque no de manera sólida y estable en el tiempo, como sí lo hicieron partidos como el Conservador, Liberal, Radical, Comunista o Socialista. En este punto, emerge uno de los grandes aportes del libro: entregar información sólida respecto a la existencia de pequeños partidos, algunos de ellos con una existencia, en lo organizacional, tan corta como una elección presidencial. Fernández identifica un conjunto de movimientos que, a pesar de cambiar sus nombres en cada elección, muestran una coherencia discursiva en el tiempo, en tanto representantes de un pensamiento nacionalista, anticomunista y, a la vez, anticapitalista, algo muy propio del eclecticismo de los movimientos populistas. Esto resulta del todo novedoso, toda vez que el libro logra hacer más complejo el entendimiento que se deberá hacer del ibañismo como movimiento. De aquí en adelante no se lo podrá ligar solamente al nazismo chileno, en el caso de las elecciones de 1938, o al Partido Agrario Laborista (PAL), en el proceso de $1952^{1}$.

Otro gran aporte del libro de Joaquín Fernández es lograr describir, de manera documentada, y con un análisis lo suficientemente persuasivo para adherir a él, cómo un movimiento populista, como el ibañismo, se insertó dentro de un sistema de partidos institucionalizado. En este sentido, queda claro que, a pesar de contar con un discurso contrario a la política y los políticos, Ibáñez y sus seguidores, en lugar de tener una actuación asistémica, fueron capaces formar alianzas con diferentes sectores. En gran medida, eso fue posible por la plasticidad del discurso populista con que actuaba en política el general Ibáñez, la que le permitía, sin riesgo a traicionar sus postulados nacionalistas, moverse entre la izquierda y la derecha, y exaltar a figuras cuya similitud no es tan clara, como Diego Portales y José Manuel Balmaceda.

En 1938, tras presentar una opción de nacionalismo revolucionario, y al verse sin posibilidades de ganar las elecciones, apoyó al Frente Popular, con quien compartía su rechazo al capitalismo y la especulación ${ }^{2}$. En 1942, logró el apoyo de la derecha, salvo sectores alessandristas del Partido Liberal, para sus pretensiones presidenciales, recurriendo, en esta ocasión, al anticomunismo como leit motiv. En 1952 llegó a la Presidencia de la República gracias al fuerte arraigo que tuvo en la

Sobre el PAL, véase Garay (1990).

Aunque, como en el libro se muestra, existen rumores respecto a que intentó obtener el poder por la fuerza. 
población, especialmente en las mujeres, su promesa de barrer con la corrupción radical y los políticos profesionales (p. 192). En esta última elección logró que una facción del hasta ese momento dividido socialismo chileno (el Partido Socialista Popular) lo apoyara.

Como el mismo Fernández muestra, esto fue posible gracias a que el ibañismo fue una sensibilidad que logró infiltrarse, incluso, dentro de distintos partidos políticos. Al analizar los intentos de Ibáñez por lograr que, en 1938, el Frente Popular lo levantara como su candidato, el autor describe cómo esta opción fue analizada seriamente por algunas de las facciones del Partido Socialista y el Partido Radical, que mostraban importantes cuotas de entusiasmo hacia la figura del ex general

Dos son las principales limitaciones del libro, que apuntan más bien a cuestiones de forma y que en ningún caso comprometen la validez de las interpretaciones propuestas por Fernández. En primer lugar, se extraña un capítulo en el que se aborde la figura de Ibáñez como político en el periodo anterior a 1937. El general, al retornar al país, ya era un político con una importante participación en la vida nacional. Como se planteó más arriba, en la década de 1920, junto a Alessandri (aunque los dos fueran personajes antagónicos), contribuyó a la modernización de la actividad política, pasando desde un juego de camarillas a una actividad íntimamente relacionada con el contacto con las masas. A ello se suma la importante participación que tuvo, junto a un grupo de ingenieros liderados por Pablo Ramírez, en la modernización de la administración pública (Ibáñez, 1983, 2003; Silva, 1994).

En segundo lugar, se extraña una discusión mayor del autor con quienes lo precedieron en el esfuerzo por entender la figura de Ibáñez, y con la literatura que teóricamente ha analizado el populismo en Latinoamérica. Si bien Fernández demuestra conocer gran parte de estos estudios -incluso citándolos-, se muestra mezquino con el lector, toda vez que no profundiza en las causas que lo llevan a afirmar que los trabajos existentes sobre el ibañismo presentan limitaciones.

En todo caso, estas cuestiones resultan anecdóticas en comparación con la gran riqueza de interpretaciones que el libro entrega y las nuevas líneas de investigación que abre. Es digno de destacar que estas últimas no solamente se limitan al campo historiográfico, sino que también al de la ciencia política y al de la administración pública. Por una parte, la posibilidad de que un movimiento populista logre cohabitar con un sistema de partidos estable es un tema que debiese ser abordado por otras investigaciones. Quizás esto responde a una característica propia del sistema político chileno. Téngase en cuenta que otros liderazgos que se han presentado como antipoliticos, como el neopulismo de Joaquín Lavín, fue levantado por un sector que forma parte del propio sistema de partidos. En este sentido, existe una diferencia entre Chile y otros países, como Perú o Venezuela, donde los populismos que surgieron en la década de 1990, sea en su vertiente tradicional o neo, tuvieron como principal objetivo derribar los sistemas de partidos existentes y la institucionalidad formada por éstos. 
Por otra parte, y aunque no es el interés del libro de Fernández, la evidencia presentada por él permite establecer algunas ideas tentativas respecto al tipo de pensamiento administrativo que el nacionalismo chileno ha creado. El ibañismo, en un tono moralista y redentor constantemente utilizó, para denigrar a sus adversarios políticos, la idea de corrupción administrativa, y la denuncia de los nefastos efectos que la intromisión política generaba en la administración pública. Estas pistas debiesen ser retomadas para entender cómo el nacionalismo influyó en la formación de la administración pública chilena, sobre todo si se tiene en cuenta que Ibáñez fue el principal impulsor de dicho proceso.

\section{Referencias}

IbÁÑEZ, Adolfo. 1983. "Los Ingenieros, el Estado y la Política en Chile. Del Ministerio de Fomento a la Corporación de Fomento, 1927-1939". Historia 18: 45-102.

IBÁÑEZ, AdOLFO. 2003. Herido en el Ala. Estado, Oligarquias y Subdesarrollo. Chile 19241960. Santiago: Biblioteca Americana.

Garay, CristiÁn. 1990. El Partido Agrario Laborista. Santiago: Editorial Andrés Bello.

Scully, Timothy. 1992. Los Partidos de Centro y la Evolución Política Chilena. Santiago: CIEPLAN-Notre Dame.

Silva, PATriCiO. 1994. State, Public Technocracy and Politics in Chile, 1927-1941. Bulletin of Latin American Research, 13 (3): 281-297.

Silva, PATRICIO. 2006. Los Tecnócratas y la Política en Chile: Pasado y Presente. Revista de Ciencia Política 26 (2): 175-190.

Valenzuela, Arturo y J. Samuel Valenzuela. 1983. Los Orígenes de la Democracia. Reflexiones Teóricas sobre el Caso de Chile. Estudios Públicos 12: 7-39.

Valenzuela, J. SAmuel. 1995. Origenes y Transformaciones del Sistema de Partidos en Chile. Estudios Públicos 58: 6-80. 